\title{
Identifying functional factor for developing the community centre in Kuala Lumpur
}

\begin{abstract}
Malaysian community centres in city like the developed countries is too bear the responsibility of providing community facilities to the urban mass. Community centre is one of the main social facilities with the purpose of facilitating community interaction and finally, contributing community development in urban areas. The study frames by in-depth interview with the deputy director of urban design, building department and professional expert in urban design project. this study assessed approaches that participations can use to evaluate critical factors for developing the community centres. A city like Kuala Lumpur, where scarcity of spaces for community gathering and interaction is severe, it is urgent to resolve the problems and enhance the potentials for ensuring effective and multipurpose uses of the community centres. This research approaches that community centre can be a pole of community development.
\end{abstract}

Keyword: Community centre; Functional considerations 